\title{
Perfectionist Types in the English as a Foreign Language Teaching Profession in Russia
}

\author{
Kenneth Wang \\ Fuller Theological Seminary \\ Correspondence concerning this article should be addressed to Kenneth Wang, Associate Professor of \\ Psychology, Department of Clinical Psychology, 135 N Oakland Ave, Pasadena, CA 91101, USA. \\ E-mail: kennethtwang@gmail.com
}

Tatiana M. Permyakova

National Research University Higher School of Economics Correspondence concerning this article should be addressed to Tatiana M. Permyakova, National Research
University Higher School of Economics, Department of Foreign Languages, National Research University
Higher School of Economics, 38 Studencheskaya, Perm, Russian Federation. E-mail: tpermyakova@hse.ru

\author{
Marina S. Sheveleva \\ National Research University Higher School of Economics
}

\begin{abstract}
Correspondence concerning this article should be addressed to Marina S. Sheveleva, Department of Foreign Languages, National Research University Higher School of Economics, 23 Studencheskaya, Perm, Russian Federation. E-mail: msheveleva@hse.ru
\end{abstract}

\begin{abstract}
This study examines perfectionism in the English language teaching profession in Russia. The aims are threefold: 1) to use latent profile analysis (LPA) to classify English as a foreign language (EFL) teachers into different types of perfectionists; 2 ) to compare different types of perfectionists using depression-anxiety-stress indicators (DASS); 3) to study the link between perfectionism and the perception of one's professional teaching activity. We used convenience sampling by collecting data from 117 English teachers (5\% males, 95\% females; age range 2064; $\mathrm{M}=39 ; \mathrm{SD}=12$ ) with the Short Almost Perfect Scale (SAPS) and the Depression Anxiety Stress Scale-21 (DASS-21). LPA was conducted to determine the optimal number of types of individuals based on their SAPS profile. Three distinct classes of perfectionists were found (adaptive, maladaptive, non-perfectionists). 27\% of the respondents fell into the category of maladaptive perfectionists with high scores on both the Standards and Discrepancy subscales. Teachers with higher Standards tend to be more aware of their perfectionism. Teachers who are less satisfied with their English proficiency tend to be more stressed at work. However, the results of the study did not indicate significant differences between the perfectionist types on anxiety, depression, and stress. The findings suggest the need to develop these scales further for measuring perfectionism in the teaching profession and in EFL teaching particularly.
\end{abstract}

Keywords: perfectionism; Short Almost Perfect Scale; adaptive perfectionists; maladaptive perfectionists; EFL teaching profession; latent profile analysis

\section{Introduction}

Perfectionism is regarded as a personality trait with positive and negative implications that affects all aspects of human life (Fletcher \& Shim, 2019; Rice \& Slaney, 2002; Stoeber \& Otto, 2006). Although early studies mainly focused on its negative side and positive correlations with psychological distress indicators (Stoeber \& Otto, 2006), perfectionism has been studied as a multidimensional construct since the 1990s. The acceptance of the multidimensional nature of this construct resulted in a number of studies classifying individuals into different types of perfectionists. The different types of perfectionists, along with nonperfectionists, were first identified in Rice and Slaney's (2002) study using the Almost Perfect Scale-Revised (APS-R; Slaney, Rice, Mobley, Trippi, 
\& Ashby, 2001). Although there are other measures of perfectionism (for example, The Multidimensional Perfectionism Scale (MPS; Hewitt \& Flett, 1991), the APS-R has been the perfectionism measure most often used to classify individuals into these different types. A short form of APS-R has recently been developed Short Almost Perfect Scale (SAPS; Rice, Richardson, \& Tueller, 2014) and the translated version was validated for the Russian sample (Wang, Permyakova, \& Sheveleva, 2016). The SAPS core subscales used to differentiate perfectionists are "Standards" and "Discrepancy". "Standards" measure the level of high expectations one has for him or herself. "Discrepancy" measures the perceived gap between one's ideal standards and performance. Adaptive perfectionists are characterized as having high "Standards" and relatively low "Discrepancy" between their standards and performance. Maladaptive perfectionists have both high "Standards" and "Discrepancy". Individuals who scored low on both "Standards" and "Discrepancy" are labeled as nonperfectionists.

\section{Theoretical Overview}

A number of studies have examined perfectionism in relation to professional field in different countries' samples. Slaney, Ashby, and Trippi (1995) discussed how the construct of perfectionism is potentially important for career choice and career development. Further studies demonstrated that the meaning and the measurement of perfectionism can be related to a variety of career variables (Akre, Falkum, Hoftvedt, \& Aasland, 1997; Berry, 2002; Li, Hou, Chi, Liu, \& Hager, 2014; O’Brien \& Page, 1994; Pawlowski, Kaganer, \& Cater, 2007).

A substantial body of research affirmed the emotional nature of the teaching profession (Mawhinney \& Rinke, 2018; Taxer, Becker-Kurz, \& Frenzel, 2019), which is often found as the most credible explanation in linking perfectionism with distress variables such as anxiety, stress, and burnout (Comerchero, 2008; Kenny, Davis, \& Oates, 2004; Stoeber \& Rennert, 2008; Travers \& Cooper, 1996). For instance, researchers explained the association between dimensions of perfectionism and indices of job stress (the intensity and frequency of professional distress, emotional manifestations, and physiological manifestations) and perceptions of organizational support (measures of job satisfaction, job expectancy, and absenteeism) in teachers and coaches (Flett, Hewitt, \& Hallett, 1995; Tashman, Tenenbaum, \& Eklund, 2010). A significant association was also detected between socially prescribed perfectionism and low job satisfaction. It was concluded that social expectations of perfectionism are highly relevant to the understanding of teacher stress. Similar findings in relation to coping, maladaptive perfectionism, and stress were found in university professors (Dunn, Whelton, \& Sharpe, 2006).

There are only a few studies on perfectionism in English as a Foreign Language (EFL) teachers. MahmoodiShahrebabaki (2017) investigated the correlations between perfectionism and burnout levels among 276 Iranian EFL teachers. The findings revealed that, compared to other dimensions of burnout, depersonalization was more significantly affected by both direct and indirect effects of perfectionism. Moreover, the statistically insignificant direct associations between perfectionism and emotional exhaustion became significant due to the intervening impact of anxiety.

Pishghadam, Fatemi, and Ghaviandam (2013) designed and validated a Scale on English Language Teacher Perfectionism (SELTP). The scale was constructed by picking out the most common aspects of English language teachers' perfectionistic orientations. The constructed scale was used by Ghorbanzadeh \& Rezaie (2016) to investigate the relationship between English language teacher perfectionism (SELTP), teacher burnout (Maslach Burnout Inventory), and teacher efficacy (Teacher Efficacy Scale) with a sample 114 EFL Iranian male and female teachers. Results indicated that there was a high positive correlation between perfectionism, teacher burnout, and efficacy, that female teachers were more efficacious than male ones, and that the magnitude of correlation coefficients was higher for the male participants.

A different line of research studied the relationships between three dimensions of perfectionism (self-oriented, other-oriented, and socially prescribed) and reflectivity on a sample of 289 Iranian English as a Foreign Language teachers (Shokrollahi \& Baradaran, 2014). Perfectionism was measured with The Multidimensional Perfectionism Scale (MPS; Hewitt \& Flett, 1991) and reflectivity - with The English Language Teaching Reflection Inventory (ELTRI; Akbari, Behzadpoor, \& Dadvand, 2010). The results showed that there is a statistically significant relationship between three dimensions of perfectionism and reflectivity, and perfectionism is a significant predictor of teachers' reflectivity. 


\section{Current Study}

To our knowledge, this is the first study to address perfectionism in EFL teachers in Russia despite the fact that perfectionism is deeply embedded in Russian culture (Lisauskene, 2007) and that foreign language teaching and learning in Russia is historically connected with striving for perfection and native speaker proficiency. TerMinasova, in her seminal report (2014), argues that foreign language learning and teaching in the Soviet times was based on the motto "The Soviet means the excellent" and set the same goal: to give perfect knowledge of the language being studied.

The aims of this study are threefold: 1) to use latent profile analysis to classify respondents / EFL teachers into different types of perfectionists; 2 ) to compare different types of perfectionists using mental health indicators; and 3) to study the link between perfectionism and the perception of one's professional teaching activity.

\section{Materials and Methods}

\section{Participants}

We used convenience sampling for collecting data from 117 English teachers ( $5 \%$ males, $95 \%$ females; age range $20-64 ; \mathrm{M}=39 ; \mathrm{SD}=12$ ) working in secondary schools in Russia. There was a wide age range with $22 \%$ from $20-29$, $30 \%$ from $30-39,16 \%$ from $40-49,29 \%$ from $50-59$, and $3 \%$ over 60 years old. The majority of the participants had a university level degree (96\%) and the remaining part had vocational training. In terms of years of experience in teaching, $8 \%$ had fewer than two years, $33 \%$ had $2-5$ years, $8 \%$ had $5-10$ years, $13 \%$ had $10-20$ years, and $38 \%$ had over 20 years.

\section{Procedure}

The research survey was presented in Russian and took between 20 and 30 minutes to complete. Participation was voluntary and the respondents were invited to participate in the study by staying after a workshop to complete a paper-and-pencil questionnaire. This research complied with the research ethical code of the university where it was administered. There was no financial compensation or additional incentive for participating.

\section{Measures}

Short Almost Perfect Scale (SAPS; Rice et al., 2014). The SAPS consists of two subscales - "Standards" (4 items; e.g. "I have high expectations for myself.") and "Discrepancy" (4 items; e.g. "Doing my best never seems to be enough.”) and is used to measure perfectionism. The Standards' subscale measures the level of perfectionistic striving by assessing one's setting of high expectations. The "Discrepancy" subscale measures the level of perfectionistic concerns by assessing each participant's tendency to perceive a gap between their standards and performance. The SAPS was translated into Russian on the basis of three-step back-translation guidelines (Wang et al., 2016). Participants rated each item on a seven-point Likert scale: 1 (strongly disagree) to 7 (strongly agree). The Cronbach alphas ranged from .85 to .87 for "Standards" and .84 to .87 for "Discrepancy" in the original scale development study (Rice et al., 2014). In this study, the Cronbach alphas for the Standards and Discrepancy scores were .72 and .62, respectively.

Depression Anxiety Stress Scale-21 (DASS-21; Lovibond \& Lovibond, 1995). The DASS assesses the levels of depression, anxiety, and stress. It includes three subscales: "Depression" (7 items; e.g., "I couldn't seem to experience any positive feeling at all."), "Anxiety" (7 items; e.g., "I was aware of dryness of my mouth.”), and "Stress" (7 items; e.g., "I found it hard to wind down."). The DASS is rated on a four-point Likert scale: 0 (did not apply to me at all) to 3 (applied to me very much, or most of the time). The Russian version of the DASS was obtained from the DASS website. In a previous study, Cronbach alphas for the "Depression, Anxiety, and Stress" subscale scores were .90, .88, and .91, respectively (Henry \& Crawford, 2005). In this study, the Cronbach alphas for the Depression, Anxiety, and Stress scores were .74, .84, and .88, respectively. 
Additional Questions. Four additional questions were asked: 1) Do you agree with the statement that you are a perfectionist? (rated on the scale from 1 (completely disagree) to 5 (completely agree); 2) Have you ever been called a perfectionist? (rated on the scale from 1 (no, never) to 3 (yes, often); 3) How satisfied are you with your English language competency? (rated on the scale from 1 (completely dissatisfied) to 5 (completely satisfied); 4) How satisfied are you with your students' English competency? (rated on the scale from 1 (completely dissatisfied) to 5 (completely satisfied).

Statistical Method. First, a bivariate correlation was conducted using SPSS 22 to examine the strength and direction of associations across all study variables. Next, latent profile analysis (LPA) was conducted in this study through Mplus 7 to classify participants into different profiles of perfectionist. Finally, the auxiliary function in MPlus 7 was conducted to compare the profiles of perfectionists on various study variables using posterior probability-based multiple imputations. Below, we provide a description of LPA and the advantages of using this method.

LPA is a person-centered approach that classifies individuals based on shared characteristics of their perfectionism scores. Methodologically, we used a person-centered approach (i.e. focusing on classifying individuals into distinct profile groups and identifying characteristics of each profile group) in the present study to classify profile types of perfectionists, as opposed to a variable-centered approach (e.g., regression, correlations) that focuses on examining the relationships among variables. LPA is considered a more advanced statistical method across different person-centered approaches. Compared to cluster analysis, which is a common method used to classify individuals into perfectionist types, LPA allows researchers to identify latent constructs based on membership probability that best describe each profile group from multiple observed variables (McCutcheon, 1987). Participants' group membership is based on underlying latent variables (Nylund, Asparouhov, \& Muthén, 2007). In other words, unlike cluster analysis, LPA does not assign group memberships. Instead, probabilities associated with each group are calculated for each participant.

For a model-based approach like LPA, fit statistics and significance tests are used to determine the class solution. A number of indicators are used to determine the model fit in LPA. Bayesian information criterion (BIC; Schwartz, 1978) is considered the best indicator of true model fit (Nylund et al., 2007). Additionally, the Lo-Mendel-Rubin test (Lo, Mendell, \& Rubin, 2001) compares the model fits between two nested models that differ by one class. Specifically, a significant adjusted Lo-Mendell-Rubin Likelihood Ratio Test (aLRT) $p$ value indicates whether the model fit of a certain solution is significantly better than the solution with one fewer class. Lastly, entropy was used to evaluate the precision of classification for each solution.

\section{Results}

\section{Intercorrelations}

Correlation analysis was conducted between the study variables and the results are shown in Table 1 . In this Russian sample, "Standards" and "Discrepancy" were minimally correlated $(r=-.17)$. "Perfectionistic Standards" was positively correlated with the extent to which participants viewed themselves as perfectionists. This means that those teachers who labeled themselves as perfectionists scored high on such scale items as "I expect the best from myself." and "I have a strong need to strive for excellence." However, "Perfectionistic Discrepancy" was not significantly correlated with participants' view of whether they were perfectionists. Neither "Perfectionistic Standards" nor "Discrepancy" were significantly correlated with whether others viewed the participant as a perfectionist.

The "Perfectionistic Discrepancy" subscale was significantly and positively correlated with "Anxiety, Depression, and Stress". In this sample, the teachers who had high scores on such scale items as "I am hardly ever satisfied with my performance." and "I often feel disappointment after completing a task because I know I could have done better." demonstrated higher levels of anxiety and depression. However, perfectionistic Standards were not significantly correlated with any of the distress variables.

Interestingly, there was significant and positive correlation $(r=.44)$ between those who agreed with the 
statement that they are perfectionists and those who had been called perfectionists by others.

Table 1

Intercorrelations Between Study Variables

\begin{tabular}{lcccccccccc}
\hline & $\mathbf{1}$ & $\mathbf{2}$ & $\mathbf{3}$ & $\mathbf{4}$ & $\mathbf{5}$ & $\mathbf{6}$ & $\mathbf{7}$ & $\mathbf{8}$ & Mean & SD \\
\hline Standards & - & - & - & - & - & - & - & - & 19.26 & 4.00 \\
Discrepancy & -.17 & - & - & - & - & - & - & - & 19.26 & 4.00 \\
Anxiety & .03 & $.39^{* * * *}$ & - & - & - & - & - & - & 4.45 & 4.31 \\
Depression & .01 & $.38^{* * * *}$ & $.72^{* * * *}$ & - & - & - & - & - & 4.91 & 3.59 \\
Stress & .09 & $.22^{*}$ & $.70^{* * * *}$ & $.68^{* * * *}$ & - & - & - & - & 8.53 & 4.88 \\
Perfectionist-Self & $.27^{* * *}$ & -.07 & .02 & .12 & .02 & - & - & - & 3.25 & 0.99 \\
Perfectionist-Other & .12 & -.12 & .02 & .09 & .03 & $.44^{* * * *}$ & - & - & 1.83 & 0.88 \\
EngSat-Self & .15 & -.13 & -.08 & -.13 & $-.26^{* * *}$ & .03 & -.01 & - & 3.06 & 1.01 \\
EngSat-Students & .01 & -.06 & -.02 & -.14 & -.06 & .02 & .00 & .07 & 2.84 & 0.96 \\
\hline
\end{tabular}

Note. ${ }^{*} \mathrm{p}<.001 . \mathrm{N}=117$.

\section{Latent Profile Analysis of SAPS Item Scores}

We conducted latent profile analyses (LPA) to determine the optimal number of distinct types of individuals based on their SAPS perfectionism profile. All eight SAPS item scores were used as LPA indicators. The first step was to determine the optimal class solution for the data by examining the Bayesian information criterion (BIC; Schwartz, 1978), the sample-size adjusted Bayesian information criterion (aBIC; Sclove, 1987), and the Lo-Mendel-Rubin adjusted likelihood ratio test (LMR; Lo et al., 2002). For all these indices, smaller values indicate a better model fit. Entropy values, for which closer to 1.0 indicates better classification precision, were also examined. Theory, parsimony, class prevalence, and interpretability (percent of participants and unique information provided by an additional class) were also important factors to consider in deciding the number of classes (Jung \& Wickrama, 2008).

LPA fit indices for two through five class solutions are presented in Table 2. A three-class solution was selected based on this solution having the lowest BIC (2650.58). The three-class solution represented the three types of perfectionists (i.e., adaptive, maladaptive, and non- perfectionists) that fit with the theory (Hamachek, 1978) and empirical studies (e.g., Rice \& Ashby, 2007, Rice et al., 2014). The three classes included: (a) those that scored high on "Standards", but relatively low on "Discrepancy" items (Adaptive Perfectionists; 34\%), (b) those exhibiting high scores on both "Standards" and "Discrepancy" items (Maladaptive Perfectionists; 27\%), and (c) a group with low scores on both "Standards" and "Discrepancy" items (Nonperfectionists, 39\%). The estimated SAPS means of each predicted group membership from the LPA are presented in Figure 1, Appendix.

Table 2

Fit Indices Latent Profile Analyses for 2 to 5 Class Models

\begin{tabular}{rccccc}
\hline Model & LL & BIC & aBIC & aLRT p & Entropy \\
\hline 2-class model & -1281.12 & 2681.29 & 2602.26 & .019 & 0.72 \\
3-class model & -1244.33 & 2650.58 & 2543.10 & .269 & 0.81 \\
4-class model & -1227.88 & 2660.54 & 2524.61 & .101 & 0.86 \\
5-class model & -1212.60 & 2672.84 & 2508.46 & .648 & 0.88 \\
\hline
\end{tabular}

Note. $\mathrm{LL}$ = log likelihood; BIC = Bayesian information criterion; aBIC = adjusted Bayesian information criterion; aLRT p = adjusted LoMendell-Rubin Likelihood Ratio Test $\mathrm{p}$ value. Smaller values indicate a better fit of the model. Entropy values close to 1.0 indicate higher classification precision. All entropy ratings indicate acceptable fit.

\section{Comparing Perfectionist Types}

The three classes of perfectionist types were compared on the basis of the study variables (see Table 3). We used the auxiliary function in MPlus to conduct the equality of tests of means across classes using posterior probability-based multiple imputations. The results did not indicate any significant differences between 
the perfectionist types on measures of distress. However, the estimated mean values point to maladaptive perfectionists having higher levels of distress.

Table 3

Estimated Means by Perfectionists Types on Study Variables

\begin{tabular}{|c|c|c|c|c|c|c|c|}
\hline \multirow[b]{2}{*}{ Variable } & \multicolumn{2}{|c|}{ Adaptive Perfectionists $37 \%$} & \multicolumn{2}{|c|}{ Maladaptive Perfectionists 24\% } & \multicolumn{2}{|c|}{ Non-Perfectionists $39 \%$} & \multirow[b]{2}{*}{$\operatorname{Sig}(p<.05)$} \\
\hline & M & SE & M & SE & M & SE & \\
\hline Standards & 22.55 & 0.42 & 19.54 & 0.61 & 15.92 & 0.45 & $\mathrm{NP}<\mathrm{MP}<\mathrm{AP}$ \\
\hline Discrepancy & 10.97 & 0.42 & 17.82 & 0.56 & 13.37 & 0.41 & $\mathrm{AP}<\mathrm{NP}<\mathrm{MP}$ \\
\hline Anxiety & 3.77 & 0.63 & 5.24 & 0.86 & 4.60 & 0.71 & non-sig \\
\hline Depression & 4.49 & 0.54 & 5.88 & 0.73 & 4.70 & 0.58 & non-sig \\
\hline Stress & 8.42 & 0.75 & 8.85 & 0.97 & 8.44 & 0.77 & non-sig \\
\hline
\end{tabular}

Note. $\mathrm{N}=117$.

\section{Discussion}

The first aim of this study was to classify and examine different types of perfectionists in a sample of Russian EFL teachers using latent profile analysis. Three distinct classes of perfectionists were found (adaptive, maladaptive, non-perfectionists). $24 \%$ of the respondents fell into the category of maladaptive perfectionists with high scores on both "Standards" and "Discrepancy" subscales. This means that almost a quarter of the respondents fell into the "risk category".

The second aim was to compare different types of perfectionists using mental health indicators. However, the results of the study did not indicate significant differences between the perfectionists types for anxiety, depression, and stress. This raises the issue of whether a new scale to measure perfectionism in teachers, especially EFL teachers, is needed.

Thirdly, the study showed the link between perfectionism measures and the way EFL teachers perceive the way they work. The results demonstrated that teachers with higher Standards tend to be more aware of the fact that they are perfectionists. Moreover, teachers who are less satisfied with their English proficiency tend to be more stressed at work. If this is the case, teachers might be concerned with their self-image and strive for perfection to reduce the possibility of not knowing something within the field of their professional expertise. Taking into account the excessive external demands within the education system in Russia and the lack of consistent support from employers, teachers are likely to develop perfectionistic qualities within the working environment. These findings are in line with previous studies on perfectionism among professionals with complex jobs. In addition, higher discrepancy scores in the maladaptive perfectionist class resonate with previous results on higher levels of distress variables, which may indicate the need to look deeper into discrepancy dimensions of the construct. With reference to applying these findings, developing coping mechanisms may remain problematic. This can be taken into consideration for continuous professional development programs, mentorships, and assessment, as well as more general programming issues for occupational psychological well-being (Gordeeva, Sychev, \& Osin, 2010; Leontiev, Mandrikova, Osin, Plotnikova, \& Rasskazova, 2007).

Another point of interest in the findings is the strong connection between perfectionistic standards and the ability to recognize one's own perfectionism in the EFL teachers' sample. While it supports the results of Shokrollahi \& Baradaran (2014), who posited that perfectionism is linked with reflectivity in EFL teachers, it also deepens the understanding of this link. As reflectivity in the teaching profession is believed to have a positive impact on work effectiveness (Larsen-Freeman, 2000), this finding adds to the understanding of the positive dimensions of perfectionism. Reflection is an essential part of teachers' professional development, which is why deliberative self-assessment with a valid instrument and implementing knowledge into instructional practice will help EFL teachers become more aware and more skilled at incorporating perfectionism evidence with the possibility of foreseeing the consequences of their actions. In turn, these may promote a further cycle of teachers' self-inquiry. 
This study has practical implications for the professional longevity of EFL teachers. Almost a quarter of the respondents fell in the category of maladaptive perfectionists. Previous studies showed a strong link between maladaptive perfectionism, low job satisfaction, and professional burn-out. Thus, the professional longevity of EFL teachers might have a link to the psychological characteristics of perfectionism. Understanding this link could add to the range of ways to retain EFL teachers in the profession. In light of the literature overview, further prospects to relate career variables such as intrinsic-extrinsic motivation, burnout, workaholism, to the classes of perfectionists might be helpful. Stress and coping strategies in regard to teaching experience and organizational structure may also be worth investigating.

\section{Conclusion}

The current study showed three distinct classes of perfectionists, with almost a quarter of the respondents falling into the category of maladaptive perfectionists. The need to develop a scale to measure teacher perfectionism was also discussed.

Several limitations of this study should be mentioned. First, the limited sample size with uneven gender distribution should be taken into account. The sample in this study was predominantly female (95\%). It should be noted though that this sample reflects the gender distribution in the EFL teaching profession in Russia. Future studies may benefit from a larger sample size with a higher percentage of male respondents. Second, no statistically significant differences were found on the measures of distress between the perfectionist types. Further studies could be conducted to examine the reasons behind these findings. Third, a qualitative study could give a better understanding of how perfectionism impacts the teaching profession.

Despite the limitations discussed above, we believe that the results of this study could be used to draw attention to the issue of teacher perfectionism and its influence on the way students are taught. Teachers could become more aware of the emotional challenges of perfectionism and the way this personality traits shape the way they teach.

\section{Conflict of Interest}

The authors declare that they have no conflict of interest.

\section{References}

Akbari, R., Behzadpoor, F., \& Dadvand, B. (2010). Development of English language teaching reflection inventory. System, 38(2), 211-227. https://doi.org/10.1016/j.system.2010.03.003+++

Akre, V., Falkum, E., Hoftvedt, B. O., \& Aasland, O. G. (1997). The communication atmosphere between physician colleagues: Competitive perfectionism or supportive dialogue? A Norwegian study. Social Science \& Medicine, 44(4), 519-526. https://doi.org/10.1016/S0277-9536(96)00178-5

Berry, J. W. (2002). Cross-cultural Psychology: Research and applications. Cambridge, UK: Cambridge University Press.

Comerchero, V. (2008). Gender, tenure status, teacher efficacy, perfectionism and teacher burnout. Bronx, NY: Fordham University.

Dunn, J. C., Whelton, W. J., \& Sharpe, D. (2006). Maladaptive perfectionism, hassles, coping, and psychological distressinuniversity professors.Journal ofCounseling Psychology,53(4),511-523. https://doi.org/10.1037/00220167.53.4.511

Fletcher, K. L., \& Shim, S. S. (2019). How do adolescents approach social relationships? The cost of perfectionistic concerns. Personality and Individual Differences, 147, 177-182. https://doi.org/10.1016/j.paid.2019.04.029

Flett, G. L., Hewitt, P. L., \& Hallett, C. J. (1995). Perfectionism and job stress in teachers. Canadian Journal of School Psychology, 11(1), 32-42. https://doi.org/10.1177/082957359501100105 
Ghorbanzadeh, A., \& Rezaie, G. (2016). The relationship between English language teacher perfectionism, efficacy, and burnout. International Journal of Foreign Language Teaching and Research, 4(14), 97-106.

Gordeeva, T. O., Sychev, O. A., \& Osin, Ye. N. (2010). Razrabotka russkoyazychnoy versii testa dispozitsionnogo optimizma (LOT) [The development of a Russian version of dispositional optimism test (LOT)]. Psychological Diagnostics, 2, 36-64.

Hamachek, D. E. (1978). Psychodynamics of normal and neurotic perfectionism. Psychology: A Journal of Human Behavior, 15, 27-33.

Henry, J. D., \& Crawford, J. R. (2005). The short-form version of the Depression Anxiety Stress Scales (DASS-21): Construct validity and normative data in a large non-clinical sample. British Journal of Clinical Psychology, 44(2), 227-239.

Hewitt, P. L., \& Flett, G. L. (1991). Perfectionism in the self and social contexts: conceptualization, assessment, and association with psychopathology. Journal of Personality and Social Psychology, 60(3), 456-470. https:// doi.org/10.1037/0022-3514.60.3.456

Jung, T., \& Wickrama, K.A.S. (2008). An introduction to latent class growth analysis and growth mixture modeling. Social and Personality Psychology Compass, 2(1), 302-317. https://doi.org/10.1111/j.1751-9004.2007.00054.x

Kenny, D. T., Davis, P., \& Oates, J. (2004). Music performance anxiety and occupational stress amongst opera chorus artists and their relationship with state and trait anxiety and perfectionism. Journal of Anxiety Disorders, 18(6), 757-777. https://doi.org/10.1016/j.janxdis.2003.09.004

Larsen-Freeman, D. (2000). Techniques and principles in language teaching. Oxford, UK: Oxford University.

Leontiev, D. A., Mandrikova, E. Yu., Osin, Ye. N., Plotnikova, A. V., \& Rasskazova, E. I. (2007). Opyt strukturnoy diagnostiki lichnostnogo potentsiala [The case of structural diagnostics of personal potential]. Psychological Diagnostics, 1(1), 8-31.

Li, X., Hou, Z. J., Chi, H. Y., Liu, J., \& Hager, M. J. (2014). The mediating role of coping in the relationship between subtypes of perfectionism and job burnout: A test of the $2 \times 2$ model of perfectionism with employees in China. Personality and Individual Differences, 58, 65-70. https://doi.org/10.1016/j.paid.2013.10.007

Lisauskene, M. V. (2007). The next generation: Pragmatic perfectionists or romantics of consumption. Russian Social Science Review, 48(5), 57-67.

Lo, Y., Mendell, N. R., \& Rubin, D. B. (2001). Testing the number of components in a normal mixture. Biometrika, 88(3), 767-778. https://doi.org/10.1093/biomet/88.3.767

Lovibond, P. F., \& Lovibond, S. H. (1995). The structure of negative emotional states: Comparison of the Depression Anxiety Stress Scales (DASS) with the Beck Depression and Anxiety Inventories. Behaviour Research and Therapy, 33(3), 335-343. https://doi.org/10.1016/0005-7967(94)00075-U

Mahmoodi-Shahrebabaki, M. (2017). The effect of perfectionism on burnout among English language teachers: the mediating role of anxiety. Teachers and Teaching, 23(1), 91-105 https://doi.org/10.1080/13540602.2016. 1203776

Mawhinney, L., \& Rinke, C. R. (2018). I just feel so guilty: The role of emotions in former urban teachers' career paths. Urban Education, 53(9), 1079-1101. https://doi.org/10.1177/0042085917741726

McCutcheon, A. L. (1987). Latent class analysis (No. 64). Thousand Oaks, CA: Sage.

Nylund, K. L., Asparouhov, T., \& Muthén, B. O. (2007). Deciding on the number of classes in latent class analysis and growth mixture modeling: A Monte Carlo simulation study. Structural Equation Modeling, 14(4), 535-569. https://doi.org/10.1080/10705510701575396

O'Brien, S., \& Page, S. (1994). Self-efficacy, perfectionism, and stress in Canadian nurses. Canadian Journal of Nursing Research Archive, 26(3), 49-61.

Pawlowski, S. D., Kaganer, E. A., \& Cater, J. J. III (2007). Focusing the research agenda on burnout in IT: Social representations of burnout in the profession. European Journal of Information Systems, 16(5), 612-627. https:// doi.org/10.1057/palgrave.ejis.3000699

Pishghadam, R., Fatemi, A. H., \& Ghaviandam, S. (2013). Designing and Validating a Scale on English Language Teacher Perfectionism. The Iranian EFL Journal, 10(7), 11-22.

Rice, K. G., \& Ashby, J. S. (2007). An efficient method for classifying perfectionists. Journal of Counseling Psychology, 54(1), 72-85. https://doi.org/10.1037/0022-0167.54.1.72

Rice, K. G., Richardson, C. M., \& Tueller, S. (2014). The short form of the revised almost perfect scale. Journal of personality assessment, 96(3), 368-379. https://doi.org/10.1080/00223891.2013.838172

Rice, K. G., \& Slaney, R. B. (2002). Clusters of perfectionists: Two studies of emotional adjustment and academic achievement. Measurement and Evaluation in Counseling and Development, 35(1), 35-49. https://doi.org/10.1 080/07481756.2002.12069046

Schwarz, G. (1978). Estimating the dimension of a model. The Annals of Statistics, 6(2), 461-464. https://doi. 
org/10.1214/aos/1176344136

Sclove, S. L. (1987). Application of model-selection criteria to some problems in multivariate analysis. Psychometrika, 52(3), 333-343. https://doi.org/10.1007/BF02294360

Shokrollahi, M., \& Baradaran, A. (2014). On the relationship between Iranian EFL teachers' perfectionism and their refelectivity. International Journal of Language Learning and Applied Linguistics World, 7(3), 13-28.

Slaney, R. B., Ashby, J. S., \& Trippi, J. (1995). Perfectionism: Its measurement and career relevance. Journal of Career Assessment, 3(4), 279-297.

Slaney, R. B., Rice, K. G., Mobley, M., Trippi, J., \& Ashby, J. S. (2001). The revised almost perfect scale. Measurement and evaluation in counseling and development, 34(3), 157-165.

Stoeber, J., \& Otto, K.(2006). Positive conceptions of perfectionism: Approaches, evidence, challenges. Personality and Social Psychology Review, 10(4), 295-319. https://doi.org/10.1207/s15327957pspr1004_2

Stoeber, J., \& Rennert, D. (2008). Perfectionism in school teachers: Relations with stress appraisals, coping styles, and burnout. Anxiety, Stress, and Coping, 21(1), 37-53. https://doi.org/10.1080/10615800701742461

Tashman, L. S., Tenenbaum, G., \& Eklund, R. (2010). The effect of perceived stress on the relationship between perfectionism and burnout in coaches. Anxiety, Stress, \& Coping, 23(2), 195-212. https://doi. org/10.1080/10615800802629922

Taxer, J. L., Becker-Kurz, B., \& Frenzel, A. C. (2019). Do quality teacher-student relationships protect teachers from emotional exhaustion? The mediating role of enjoyment and anger. Social Psychology of Education, 22(1), 209-226.

Ter-Minasova, S. G. (2014, October). ELT in a Changing Russia: Traditions and Innovations: Keynote Address. Paper presented at the meeting of The Asian Conference on Education, Osaka, Japan.

Travers, C. J., \& Cooper, C. L. (1996). Teachers under pressure: Stress in the teaching profession. London, UK: Psychology Press.

Wang, K. T., Permyakova, T. M., \& Sheveleva, M. S. (2016). Assessing perfectionism in Russia: Classifying perfectionists with the Short Almost Perfect Scale. Personality and Individual Differences, 92, 174-179. https:// doi.org/10.1016/j.paid.2015.12.044 


\section{Appendix}

\section{Latent Class Profiles of SAPS Scores by Perfectionist Type}

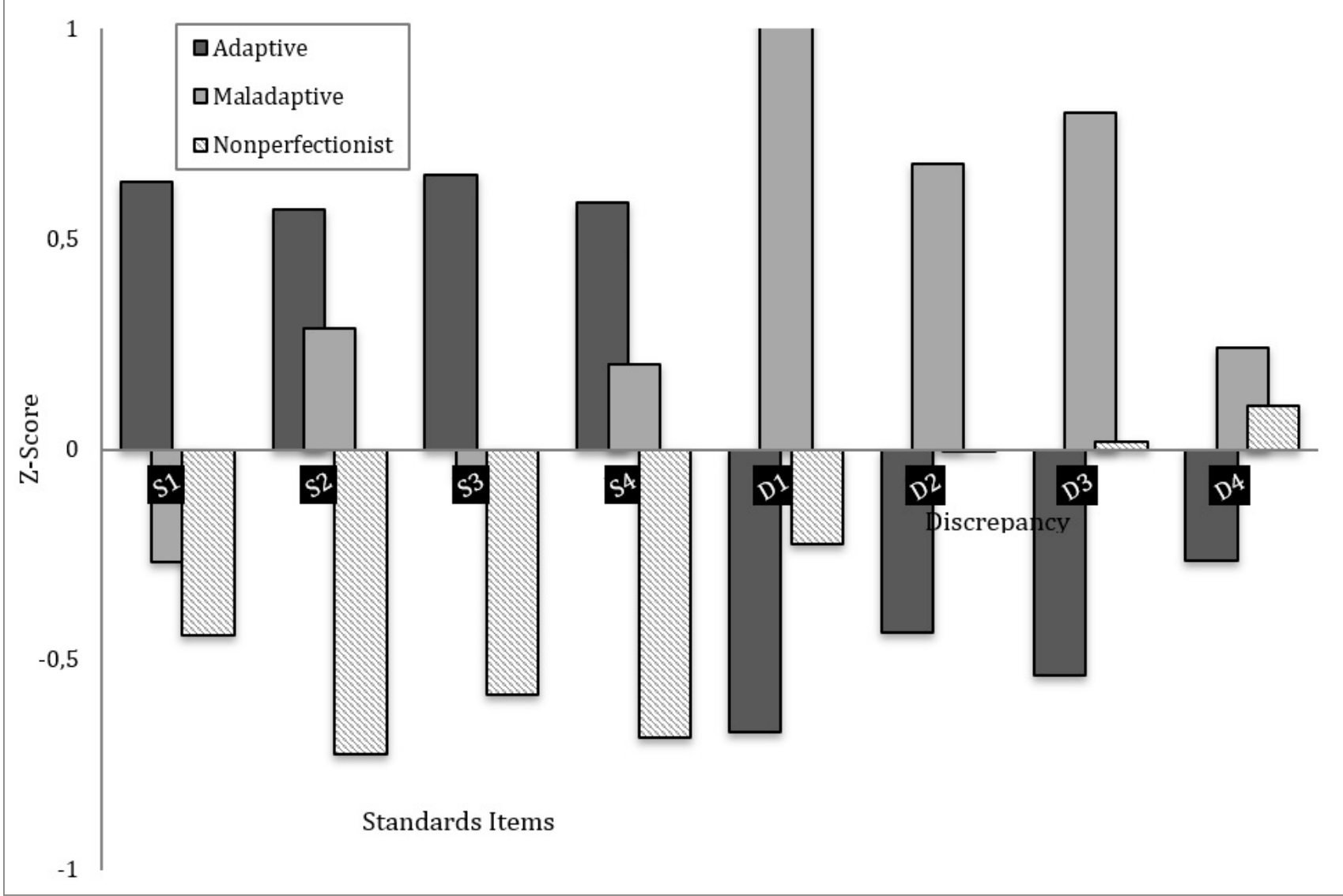

Figure 1. Latent Class Profiles of SAPS scores by Perfectionist Type. 